\title{
Esboços tropicais do Brasil: arte e política antiescravagista britânica
}

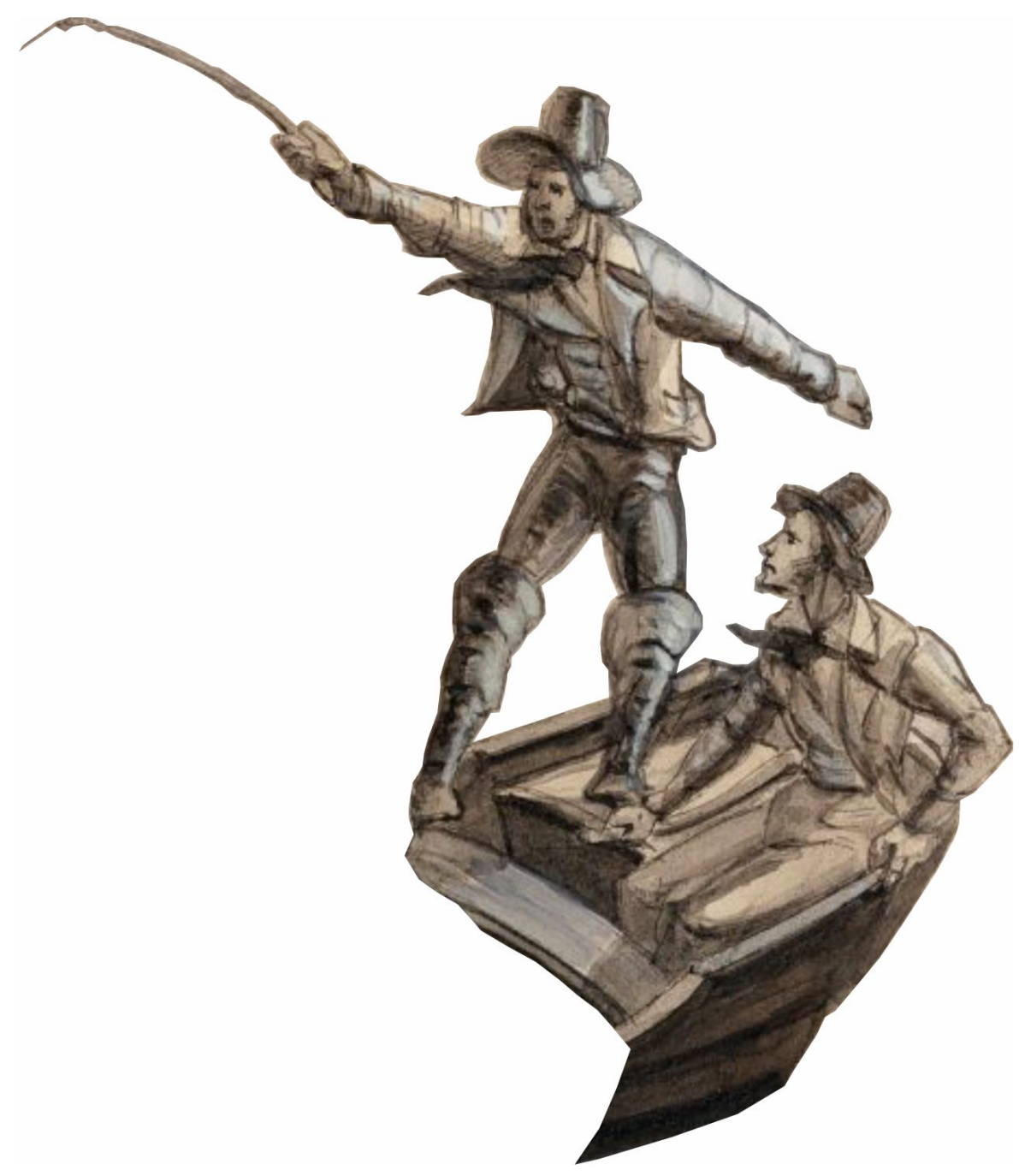

"Ilhas de Sta. Anna. Desembarque de negros escravos". Paul Harro-Harring, nanquim, aquarela e guache sobre papel, $21,3 \times 31,8 \mathrm{~cm}$, fotografia (detalhe).

\section{Emerson Dionisio Gomes de Oliveira}

Doutor em História pela Universidade de Brasília (UnB). Professor do Instituto de Artes e dos Programas de Pós-graduação em Artes e em Ciência da Informação da UnB. Pesquisador do $\mathrm{CNPa}$. Coorganizador, entre outros livros, de Historias da arte em museus. Rio de Janeiro: Rio Books, 2020. dionisio@unb.br 


\section{Esboços tropicais do Brasil: arte e política antiescravagista britânica ${ }^{1}$}

Tropical sketches from Brasil: art and British anti-slavery politic

\section{Emerson Dionisio Gomes de Oliveira}

\section{RESUMO}

Em 1840, o jornal The African Colonizer enviou o artista dinamarquês Paul Harro-Harring para o Rio de Janeiro. A viagem reverteu-se na série de pinturas intitulada Tropical sketches from Brazil. Autor de biografia controversa, Harro-Harring confeccionou um importante conjunto de obras que revelam aspectos do cotidiano da escravidão no litoral fluminense. $\mathrm{O}$ artigo busca compreender como os trabalhos de Esboços tropicais do Brasil estão relacionados às produções literária e polemista de Harring e às políticas antiescravistas britânicas, nos oferecendo condições de compreender o olhar anedótico, pontuado entre uma perspectiva lírica, o estranhamento e o registro documental. Para tanto, realizamos um levantamento documental e revisões biográficas desse artista pouco debatido, bem como, delineamos em qual projeto visual ele estava inserido.

PALAVRAS-CHAVE: Brasiliana; Paul Harro-Harring; Instituto Moreira Salles.

\begin{abstract}
In 1840 the newspaper The African Colonizer sent the Danish artist Paul Harro-Harring to Rio de Janeiro. The trip resulted in the series of paintings titled Tropical sketches from Brazil. The author of a controversial biography, Harro-Harring crafted an important set of works that reveal aspects of everyday life of slavery at the Rio de Janeiro coast. This article seeks to understand how the works of Tropical sketches from Brazil relate to Harring's literary and polemista work, setting conditions to undestanding his observational capacity, which is situated between lyric perspective, estrangement and documental registry. Works linked to an ample set of images that derives from expeditions, trips and (missions) dedicated to popularizing natural and human-made landscapes from distant lands.
\end{abstract}

KEYWORDS: Brasiliana; Paul HarroHarring; Moreira Salles Institute.

Em 1963, vinte e quatro estampas do artista Paul Harro-Harring, da série intitulada Tropical sketches from Brazil, originalmente publicadas em 1841 no periódico The African Colonizer, foram adquiridos do acervo de Don José Corradini pelo então embaixador brasileiro na França, Walter Moreira Salles. Corradini era um antiquário e colecionador italiano, radicado em Buenos Aires, que desde os anos de 1920 circulava entre os principais centros europeus e a Argentina em busca de material para comercialização e para sua própria cole-

\footnotetext{
${ }^{1}$ Este artigo é resultado de pesquisa financiada pelo CNPq.
} 
ção. Para facilitar o trânsito entre a capital argentina e Paris, nos anos 1950, ao lado de Pedro Mozzarelli, o colecionador italiano fundou a Livraria L'Amateur; especializada em livros antigos, códices, gravuras e desenhos originais de viajantes, mapas, o que atraía a atenção de bibliófilos e colecionadores de toda espécie. ${ }^{2}$ Comerciante, colecionador-expert, editor, Corradini parece ter constituído uma rede de contatos em diferentes países que lhe garantiam acesso a livros e obras raras, especialmente no pós-II Guerra. No Brasil ele trabalhou ao lado de Gilberto Ferrez e Enéas Martins na publicação em francês sobre as obras do artista viajante britânico Emeric Essex Vidal. ${ }^{3}$

Já em 1965, corroborando as táticas comuns adotadas por comerciantes especialistas como Corradini (expor-vender-publicar), os trabalhos de HarroHarring foram publicados e expostos pelo Instituto Histórico e Geográfico Brasileiro (IHGB) ${ }^{4}$ no Rio de Janeiro. Se num primeiro momento as aquarelas do artista viajante ganhavam visibilidade pública e institucional, nas décadas seguintes o conjunto seguiu discretamente dentro da política doméstica de colecionamento de Salles até a fundação do instituto homônimo início dos anos de 1990. Desde sua criação, o Instituto Moreira Salles (IMS) tem dedicado muitos recursos para preservar, expor e colecionar obras vinculadas à produção imagética sobre o Brasil; dando especial ênfase à fotografia e à produção dos chamados "artistas viajantes", dentre as mais de duas milhões de imagens acervadas. A circulação das imagens de Harro-Harring tem ganho nas últimas duas décadas um protagonismo admitido pela própria instituição. As imagens de evidente caráter narrativo têm atraído pesquisadores e educadores, que utilizam os trabalhos de Esboços tropicais do Brasil, ampliando seus usos e intepretações.

\section{Um nômade artista}

Figura de biografia polêmica, ele viajou ao Brasil no ano anterior, onde confeccionou um importante conjunto de aquarelas que revelam aspectos do cotidiano da escravidão no litoral fluminense. Seu olhar anedótico, pontuado entre uma perspectiva lírica, o estranhamento e o registro documental, vincula-se a um amplo conjunto de imagens oriundas de expedições, de viagens e de missões dedicadas a popularizar as paisagens natural e humana de terras distantes. A crítica recente revela que o tratamento conferido aos grupos sociais por Harro-Harring difere da maioria dos artistas que representaram o Brasil na primeira metade do século XIX; mas, ao mesmo tempo, o artista não deixou de expressar a "distância" do olhar europeu. Passional e parcial, seu "olhar" não dissimulou sua posição política frente à escravidão, bem como a

\footnotetext{
${ }^{2}$ Cf. TÁRTARO, Diego. Incunable jesuítico-guaraní: 'de la diferencia entre lo temporal y eterno' del padre Juan Eusebio Nieremberg S. J. Loreto 1705. Revista Cruz de Sur, año IV, n. 6, San Isidro, 2014. Disponível em $<$ http://www.revistacruzdelsur.com.ar/Numeros_001-010/RHCZDS-00611-Lo_Tartaro-Incunable_jesuiticoguarani.pdf $>$. Acesso em 10 mar. 2020.

${ }^{3}$ Cf. Picturesque illustrations of Rio de Janeiro. Paris: L'Amateur, 1961. Álbum inédito de 24 aquarelas realizadas durante os anos de 1816 a 1837. Sob a direção de José Corradini e textos introdutório e explicativo assinados por Ferrez e Martins. Tiragem: 350 exemplares numerados.

${ }^{4}$ Ver Instituto Histórico lançou álbum de Harro-Harring com cena da vida de escravos. Jornal do Brasil, Rio de Janeiro, 16 dez. 1965, p. 14.
} 


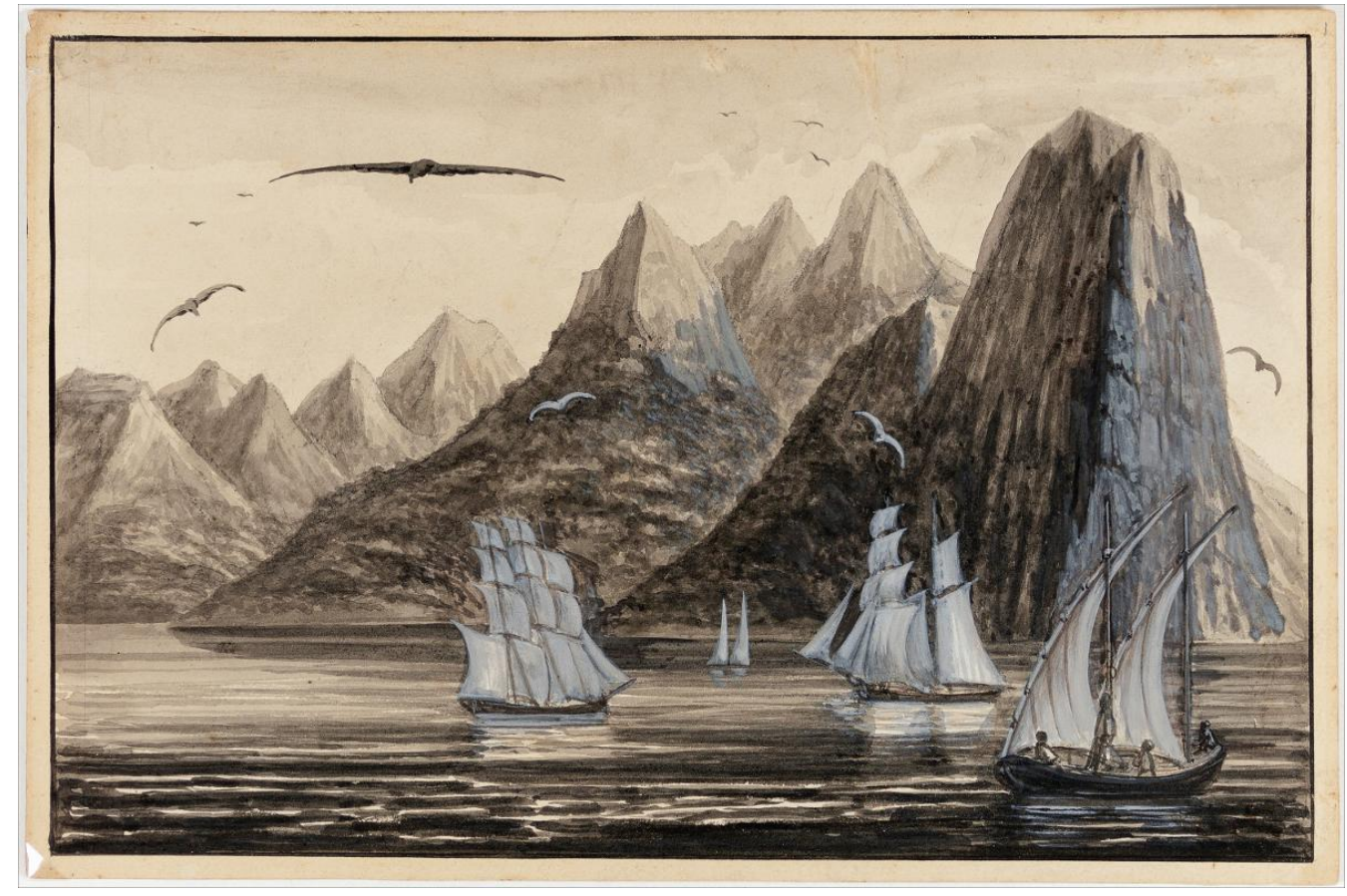

Figura 1. "Vista da costa oeste da Baía da Guanabara do Rio de Janeiro". Paul Harro-Harring, c. 1840 , aquarela e guache sobre papel, $21,5 \times 32,9 \mathrm{~cm}$.

Harro-Harring foi escritor, poeta, jornalista e ativista político com formação em artes na Academia de Copenhagen e na Academia de Dresden entre os anos de 1817 e 1822. Sua pequena produção plástica circulou entre as coleções privadas e a divulgação pública por meio de periódicos políticos e científicos. É preciso notar que seus trabalhos sobre os "brasileiros", atualmente na coleção do Instituto Moreira Sales (IMS), demonstram certa singularidade se comparados a outros viajantes do período imediatamente anterior, mas ao mesmo tempo uma similitude quanto ao trato da natureza, reverberando uma adesão aos modelos correntes da primeira metade do século XIX (figura 1). Inúmeras descrições foram feitas pelos viajantes que adentraram pela Baía de Guanabara. ${ }^{5}$ Muitos deles são relatos que exaltaram o caráter monumental e exuberante dessa paisagem: os rochedos imponentes junto às construções arquitetônicas e a natureza produziam uma imagem marcante para os que chegavam à Corte brasileira. Em seus trabalhos sobre a natureza fluminense, Harro-Harring aderiu à perspectiva panorâmica. Ao longo do século XIX, num ponto de vista geral, as imagens sobre baía ganhavam contornos mais expressivos em detrimento da necessidade do registro topográfico: “A cidade

\footnotetext{
${ }^{5}$ Anna Maria de Carvalho elenca rapidamente alguns desses artistas: “É grande o número de pintores viajantes que marcam em sua produção esse primeiro processo, tais como Richard Bates, Debret, Anderson, Ender, Bertichen, Cocholet, os Taunay (pai e filho), Chamberlain, Maria Graham, Arago, Desmond, Planitz, Rugendas, Vidal, Sunqua e Schimdt, entre outros". CARVALHO, Anna Maria. Baía de Guanabara: os itinerários da memória. Revista USP, n. 30, São Paulo, 1996, p. 164. Disponível em $<$ https://doi.org/10.11606/issn.2316-9036.v0i30p156-169>. Acesso em 8 abr. 2020.
} 
e sua natureza aparecem, na maioria das vezes, bem delineadas (predominando o desenho sobre a cor), ora em recantos ora na visão totalizadora e distanciada das perspectivas panorâmicas, dos vol-d'oiseau, sempre com a Baía de Guanabara legitimando a contundente e exuberante paisagem tropical e seus signos mais representativos (na maioria das vezes, o Pão de Açúcar)" ${ }^{6}$

Embora os trabalhos da coleção IMS tenham ganho uma visibilidade impressionante na última década, graças aos esforços de difusão da instituição colecionadora e da reprodução em programas e sítios educacionais, além de pesquisas de graduação e pós-graduação, a biografia de Harro-Harring continua sendo pouco conhecida e debatida, e não só no Brasil. Em 2006, o matemático Thomas Thode publicou as obras completas do artista, após uma década de pesquisa, recolhendo documentos dispersos em onze países. Graças a Thode podemos compreender as controvérsias abertas pelo viajante e o difuso impacto que sua obra teve na literatura política da primeira metade do século XIX.

De origem frísia, o artista nasceu em 1798 em Ibensdorf, hoje território alemão, e atuou fortemente como defensor da liberdade, no sentido conferido por diversos movimentos revolucionários de inspiração nacionalista e socialista na Europa da primeira metade dos oitocentos. Os biógrafos ${ }^{7}$ de HarroHarring são unânimes em declarar que sua formação literária sofreu forte impacto dos clássicos alemães como Goehte, Seume, Schiller, Sonnenberg e Werner. Citações das peças de Friedrich Schiller, como Don Carlo (1787), são recorrentes em seus textos. Além destes, parece ter impactado o jovem Paul a biografia romanceada escrita pelo poeta e arqueólogo Karl Ludwig Fernow chamada de A vida do artista Asmus Jacob Carstens', ${ }^{8}$ um pintor alemãodinamarquês neoclássico, cuja carreira bem-sucedida entre Berlim e Roma o aproximou de artistas mais conhecidos como Bertel Thorvaldsen e Joseph Koch. De qualquer modo, pelas indicações posteriores, Harro-Harring esteve mais fascinado com a pena Fernow que com o pincel de Carstens, mesmo diante do fato de que a obra gráfica do pintor teve reconhecida circulação no norte da Europa nas três primeiras décadas do século XIX, segundo Johannes Grave. ${ }^{9}$

Foi em Dresden, durante os anos de aprendizado de pintura histórica e de batalhas na Academia de Belas Artes, que Harro-Harring se envolveu com atividades políticas, se aproximando do grupo estudantil radical denominado Die Schwarzen von Gießen, que emprestara nome a um romance seu publicado em 1831. ${ }^{10}$ Ao longo da década de 1820, o artista de Ibensdorf transitou

\footnotetext{
${ }^{6}$ Idem.

${ }^{7}$ Salvo engano, as biografias escritas por Alexander Everett e Thomas Thode continuam sendo as principais referências.

8 Publicado em 1806, Das Lebendes Künstlers Asmus Jakob Carstens (The life of the artist Asmus Jakob Carstens) descreve Carstens como um gênio notado por poucos em seu tempo, o que para André expressa a própria excepcionalidade de Fernow. A vida do pintor, ela mesma, é tratada como obra de arte, como modelo classicista que se expressa não apenas por sua arte, mas seu caráter. Cf. ANDRÉ, Michael G. Weimar Classicism and the image of historical time. University of Michigan: Ann Arbor, 2010. Disponível em $<$ http://citeseerx.ist.psu.edu/viewdoc/download?doi=10.1.1.1034.992\&rep=rep1\&type=pdf $>$. Acesso em 10 abr. 2020.

${ }^{9}$ Cf. GRAVE, Johanne. Ideal and history. Johann Wolfgang Goethe's Collection of Prints and drawings. Artibus et Histoirae, n. 53, 2006, Cracovia, p. 178. Disponível em <http://wwwhomes.unibielefeld.de/jgrave/pub/ideal_and_history.pdf>. Acesso em 8 jun. 2019.

${ }_{10}$ Título completo publicado em Leipzig: Die Schwarzen von Giessen, oder der Deutsche Bund, 1831.
} 
entre Viena, Berlim, Roma, Munique, Paris, Praga, Varsóvia entre tantos endereços e rápidas passagens. Neste período foi detido algumas vezes por suas atividades políticas, além de exilado em duas ocasiões.

Em 1821 ingressou na Legião Philohellenica, dedicada a apoiar com dinheiro, armas e voluntários o Movimento de Libertação da Grécia contra o Império Otomano, numa coalizão das forças liberais e democráticas do período. Harro-Harring partiu para Grécia onde escreveu decepcionado que ao contrário de encontrar homens entusiastas e aventureiros, encontrou "aproveitadores e outras figuras duvidosas". ${ }^{11}$ Anos mais tarde, em sua obra autobiográfica Rhonghar Jarr12, ele escreve sobre os gregos: "Vou lhes contar em que sua calamidade se baseia, que se baseia no pântano de sua depravação moral. Porque vocês não sabem o que é liberdade, pobres gregos" ${ }^{13}$ Num diagnóstico muito próximo ao que ele fez, anos depois, dos "brasileiros brancos" e da escravidão, considerada por ele a maior das depravações morais.

Sua carreira como pintor profissional fora deixada em segundo plano após 1822, no mesmo período publicou suas primeiras obras literárias independentes. Em 1827, já como uma forma de obter rendimentos ele publica Contos de um viajante. ${ }^{14}$ No ano seguinte partiu para Varsóvia, onde envolveuse com forças nacionalistas polonesas por dois anos. Envolvimento que renderia a publicação de "Polônia sobre o domínio da Rússia", impresso em inglês simultaneamente em Londres e Boston (Estados Unidos), em 1831. Para o amigo e primeiro biografo Alexander Everett ${ }^{15}$, o livro, que hoje anacronicamente podemos chamar de "jornalismo literário" foi a obra do viajante mais prestigiada pelos pares políticos de Harro-Harring.

Everett salienta que já como membro da Constitutionellen Deutschland, o artista participou do Festival de Hambach de 1832, que o levou a ser expulso da Alemanha. Dois anos depois foi preso após participar do levante de Savoia. Estes são os anos da Vormärz alemã. Anos marcados por uma série de movimentos, ações, festivais, publicações entre 1830 e 1848 . A escritora alemã Thusnelda Kühl, que publicou Harro-Harring, der Friese ${ }^{16}$, em 1906, tipificou a literatura produzida pelo viajante como sintoma da geração Vormärz ${ }^{17}$ : inquieta, migrante, passional e fortemente combativa. Nessa mesma direção, o pesquisador Rafael Gonzaga de Macedo nos lembra que

\footnotetext{
${ }^{11}$ MARTINS FILHO, Eneas (org.). Paul Harro-Harring: Tropical sketches from Brasil, 1840. Rio de Janeiro: Instituto Histórico e Geográfico Brasileiro, 1965, p. 40.

12 Rhonghar Jarr, com o subtítulo "andanças de um frísio pela Dinamarca, Alemanha, Hungria etc." é publicado Munique, em 1828.

${ }^{13}$ HARRO-HARRING, Paul apud THODE, Thomas. Harro-Harring: eine kommentierte bibliographie seiner werke. Eutin: Eutiner Landesbibliothek, 2006, p. 193.

${ }^{14}$ Idem, Erzählungen aus den Papieren eines Reisenden. Munique, Erscheinungsjarh, Verlag: Lindauer, 1827.

${ }_{15}$ Ver EVERETT, Alexander H. Paul Harro-Harring: a biographical sketch. The United States Democratic Review, v. 15, n. 76, Nova York, ouy. 1844.

16 Ver KÜHL, Thusnelda. Harro-Harring, der Friese, Kühl. Publicado por Max Hansen (Auflage), 1906.

${ }_{17}$ Especialista na geração Vormärz, Wolfgang Schieder, ao discutir as publicações de Wilhelm Weitling e as canções "políticas esquecidas dos primeiros dias do socialismo alemão, lembra do sucesso da canção "Marseillaise" de autoria de Harro-Harring. Ver SCHIEDER, Wolfgang. Wilhelm Weitling und die deutsche politische Handwerker-Lyrik im Vormârz. International Review of Social History, v. 5, n. 2, Cambridge, 1960, p. 272. Disponível em <https://www.jstor.org/stable/44581435?read-now=1\&seq=1\#page_scan_tab_ contents>. Acesso em 10 mar. 2020.
} 
Sua atuação, nesse campo, foi tão intensa, que suas concepções políticas e filosóficas o levaram a ser perseguido e expulso por diversos governos europeus, que viam nele uma ameaça. Suas paixões e escolhas politicas constituíram a sua maneira de ver o mundo, sua Weltanschaung [concepção de mundo], deixou marcas em sua percepção e seus valores, definindo o seu hábito mental a partir do qual ele interpretou e atribuiu sentidos ao mundo por meio de suas imagens e textos. ${ }^{18}$

Assim, quando chegou para viver meses no Rio de Janeiro ${ }^{19}$, o artista trazia uma extensa bagagem como defensor republicano da liberdade e opositor convicto do trabalho servil, herança feudal na Europa, e da escravidão, em especial nas colônias e ex-colônias europeias. Andreas Gestrich lembra-nos do impacto do texto de Harro-Harring, intitulado "Carta para Lord Goderich", publicado incialmente em 1834. Mesmo sendo Goderich um empenhado articulador pelo fim da escravidão nas colônias britânicas, o artista não lhe poupou críticas, por ver na frondienst, modalidade de trabalho servil forçado, uma continuação do estatuto escravocrata, tomando a Jamaica como exemplo. ${ }^{20}$ Thode defende que este artigo atraiu a atenção dos mentores de The African Colonizer, o que resultou no convite para a viagem ao Brasil.

\section{Esboços tropicais}

Publicado em Londres por William Cecil Huttman, sob patrocínio dos colonos britânicos oriundos na África do Sul, The African Colonizer defendia uma singular perspectiva dos interesses comercias britânicos: “Os justos interesses dos colonos e os direitos dos nativos das colônias exigem igualmente a distribuição diligente de tal assunto através de periódicos exclusivamente dedicados a eles" ${ }^{21}$ Considerada até então a primeira publicação dedicada aos colonos, a revista pertenceu a tradição de periódicos britânicos antiescravocratas mantidos por políticos, intelectuais liberais e grupos religiosos, de forte viés abolicionista, cujo principal expoente da época foi o The Anti-Slavery Reporter, fundado por Zachary Macaulay, em 1825.22

Publicada entre 1840 e $1841^{23}$, The African Colonizer, patrocinador de Harro-Harring, defendia em sua política editorial a liberdade de comércio

\footnotetext{
18 MACEDO, Rafael Gonzaga de. Paul Harro-Haring: visualidade melancólica da escravidão no Rio de Janeiro -1840. Dissertação (Mestrado em História Social) - PUC-SP, São Paulo, 2014, p. 30.

${ }_{19}^{19}$ Cf. Jornal do Commercio, Rio de Janeiro, 3 maio 1840, p. 4 (Movimento do Porto. Entrada no dia 2 de maio, Rio de Janeiro), Jornal do Commercio (Saída do Porto, Rio de Janeiro, 14 de agosto de 1840). Outros periódicos indicam outras passagens rápidas do artista pelo Rio de Janeiro: Diário do Rio de Janeiro, n. 120, 2 jul. 1842, p. 4 (Movimento do Porto. Entrada do dia 1o de julho), Correio Mercantil (Saída no dia 31 de outubro de 1955, p. 1). Sobre essa última informação vale mencionar um adendo: “É provável que tenha retornado ao Rio de Janeiro, como refugiado político. A suposição tem por fundamento duas cartas enviadas por Harro-Harring para Paul Leuzinger, filho do fotógrafo suíço radicado no Rio de Janeiro, George Leuzinger, ambas firmadas na capital carioca em 1855". MARTINS FILHO, Eneas (org.), op. cit., s./p.

${ }^{20}$ Cf. GESTRICH, Andreas. The abolition act and abolitionist movements. In: LINDEN, Marcel Van Der. (org.). Humanitarian intervention and changing labor relations: the long-term consequences of the abolition of the slave trade. Leiden: Brill Academic Publishers, 2011, p. 256 e 257.

${ }^{21}$ DERRICK, Jonathan. Victorian Papers for Africa. In: Africa, Empire and Fleet Street. New York: Oxford University Press, 2018, p. 10 (tradução do autor).

${ }^{22}$ Cf. GESTRICH, Andreas, op. cit., p. 252.

${ }^{23}$ Fundado por emigrados da Cidade do Cabo, África do Sul e impresso em Londres (Cf. Spectator Review, 2, London, jan., 1841, p.17 e 18), inicialmente semanal (fevereiro de 1840), o periódico passou a ser publicado quinzenalmente em junho de 1840, aos sábados. Cf. Business and financial papers, guide. 1780-1939: selected titles from the Bodleian Library. London: Oxford and the British Library. Disponível em
} 
entre as colônias africanas. A publicação encomendou e divulgou reportagens, artigos e notícias sobre o comércio na África Ocidental, a emigração para Europa, críticas à administração colonial, informações sobre transporte, além, do tráfico de escravos. Assuntos sobre a África interessavam à Grã-Bretanha e aos seus colonos. Em seu primeiro número podemos perceber a orientação liberal do periódico, que resume: “Em suma, as possessões britânicas na África formam uma parte importante desse continente; e embora sua prosperidade dependa, em muitos aspectos, do progresso geral de todo o continente, é provável que essa prosperidade seja mais duradoura e abençoada, se os nativos das regiões menos favorecidas forem apoiados e assistidos para construir sua própria liberdade e civilização" ${ }^{24}$

A chegada ao Rio de Janeiro de Harro-Harring forneceu à revista recém-criada um panorama das condições de vida de escravos no Brasil, o que para o periódico significava mais uma estratégia contra o comércio escravocrata transatlântico, combatido pela Inglaterra, por meio de diversas associações, cujas mais proeminentes foram a Sociedade Britânica e Estrangeira Antiescravatura (BFASS, sigla em inglês da British and Foreign Anti-Slavery Society) e a Sociedade para a Extinção do Tráfico de Escravos e para Civilização da África. ${ }^{25}$ Ou seja, o olhar do artista frísio obedecia, além de sua bagagem política própria da geração Vormärz, uma direção política particular: a internacionalização das campanhas abolicionistas patrocinadas pelos britânicos. Um exemplo desse empenho está no envio do casal George e Charlotte Pilkington ao Brasil, sob os auspícios da BFASS, no mesmo período em que HarroHarring morou no Rio de Janeiro. O casal produziu um conjunto de reportagens detalhadas sobre a escravidão e o tráfico publicado no Anti-Slavery Reporter ao longo de $1841 .{ }^{26}$

Harro-Harring e outros estrangeiros chegaram ao Brasil num momento de forte mudança na política escravista do Império brasileiro. A literatura sobre o assunto é farta e foge às pretensões deste artigo ampliar tal discussão. ${ }^{27}$ Cabe-nos, todavia, pontuar que a condenação à escravidão e a ilegalidade do tráfico de africanos se transformaram em pontos de tensão entre o Império luso-brasileiro e a Coroa britânica desde o início dos oitocentos. A abolição do tráfico transatlântico de escravos nas colônias britânicas, em 1807, incitou a Grã-Bretanha a pressionar Portugal a adotar medida semelhante em relação às suas colônias, especialmente o Brasil. ${ }^{28} \mathrm{O}$ reconhecimento do status de nação

\footnotetext{
$<$ http://www.ampltd.co.uk/digital_guides/business_and_financial_papers_series_one_parts_1and2/Publish ers-Note.aspx >. Acesso em 10 jun. 2019.

${ }^{24}$ Apud Business and financial papers, guide. 1780-1939, s./p. (tradução do autor).

${ }^{25}$ Cf. RÉ, Henrique Antonio. "Missão nos Brasis": a BFASS e a organização de uma missão abolicionista secreta ao Brasil no início da década de 1840. Revista de História, n. 174, São Paulo, 2016.

${ }^{26}$ Cf. idem, ibidem, p. 96. Embora haja muitos pontos em comum entre os diferentes jornais e revista antiescravistas britânicos, as abordagens sobre o comércio de escravos no Atlântico diferiam profundamente, como atesta o estudo de Jonathan Derrick, op. cit. Ver também RÉ, Henrique Antonio. Uma história da British and Foreign Anti-Slavery Society: a instituição que internacionalizou o antiescravismo britânico. Revista de História, n. 176, São Paulo, 2017.

${ }_{27}$ Para uma discussão da literatura acadêmica sobre escravidão e cultura africana no Brasil, ver REIS, João and KLEIN, Herbert. Slavery in Brazil. In: MOYA, José C. (ed.). Handbook of Latin American History. New York: Oxford University Press, 2011.

${ }^{28}$ Cf. HASLAM, Emily. International Criminal Law and Legal Memories of Abolition: intervention, mixed Commission Courts and "Emancipation". Journal of the History of International Law, 18, Leiden, 2016. Disponivel em <https://doi.org/10.1163/15718050-12340074>. Acesso 10 abr. 2020.
} 
emancipada por parte dos britânicos, em 1826, impôs a prerrogativa de que o novo Império aboliria o tráfico nos anos seguintes..$^{29}$ Em 1831, na intenção de regular o tratado foi aprovado com o projeto de lei do marquês de Barbacena, estabelecendo que todos os escravos vindos do exterior que entrassem em portos brasileiros seriam considerados livres. Fortemente refutada e raramente aplicada ${ }^{30}$, em 1838, já sob o gabinete conservador de Araújo Lima e veemente defesa de Bernardo Pereira de Vasconcelos, o Império "facilitaria a reabertura do tráfico de maneira tácita, e assim o sustentaria durante toda a década de 1840, a despeito da repressão inglesa". ${ }^{31}$ Beatriz Mamigonian estima que cerca de 760 mil pessoas foram escravizadas ilegalmente entre 1831 e 1851.32

Assim, Harro-Harring aporta no Brasil na esteira de um processo longo de consolidação da militância antiescravocrata como política essencial da diplomacia britânica. A empreitada do artista estava delineada pelo movimento antiescravista internacional, transformado em arma geopolítica do Império britânico ${ }^{33}$, incluindo uma ampla circulação de imagens sobre a escravidão. Ao analisar um vasto material iconográfico devotado a representar a escravidão na Grã-Bretanha entre 17500-1850, Wood avalia que a variedade de imagens pró e contra a escravidão oscilaram no período, tendo as últimas predominado ao longo do século XIX. Quando publicadas, as imagens de Harro-Haring encontraram adesão ao um complexo imaginário proposto pelas imagens sobre a escravidão no Império Britânico. Wood salienta que menos que as belasartes, stricto sensu, foram as imagens artísticas produzidas para uma larga variedade de ações sociais, econômicas e culturais que impactaram a opinião pública britânica:

As imagens foram geradas pelos proprietários de escravos e por seus empregados e visitantes e assumem as formas de bordado ilustrativo, patchwork e desenhos em têxteis, esboços e desenhos de aquarelas em diários, ou pinturas decorativas em objetos domésticos e cerâmicas. Os escravos também aparecem em muitas formas de gravação em manuais técnicos relacionados às práticas agrícolas, gestão de plantações e processos de refino de açúcar e tabaco, em particular. Embora um pouco mais conhecido, também existem muitos livros de viagens ilustrados, os mais belos e de renome internacional relacionados ao Brasil, que apresentaram a escravidão por meio de uma variedade de abordagens narrativas que são polêmicas. Todas essas imagens são potencialmente valiosas no trabalho de descoberta da construção cultural da escravidão na Europa e nas Américas. ${ }^{34}$

\footnotetext{
${ }^{29}$ Cf. BETHELL, Leslie. A abolição do comércio brasileiro de escravos: a Grã-Bretanha, o Brasil, e a questão do comércio de escravos (1807-1869). Brasília: Senado Federal, 2002.

${ }^{30}$ Cf. PARRON, Tâmis. A política da escravidão no Império do Brasil, 1826-1865. Rio de Janeiro: Civilização Brasileira, 2011.

${ }^{31}$ PEREIRA, Walter Luiz Carneiro de Mattos e PESSOA, Thiago Campos. Silêncios atlânticos: sujeitos e lugares praieiros no tráfico ilegal de africanos. Estudos Históricos, v. 32, n. 66, Rio de Janeiro, 2019, p. 84.

32 Cf. MAMIGONIAN, Beatriz. O Estado nacional e a instabilidade da propriedade escrava: a lei de 1831 e a matrícula dos escravos de 1872. Almanack, n. 2, Guarulhos, 2011, p. 24.

${ }_{33}$ Cf. MARQUESE, Rafael de Bivar e PARRON, Tâmis. Internacional escravista: a política da Segunda Escravidão. Topoi, v. 12, n. 23, Rio de Janeiro, 2011.

34 WOOD, Marcus. Blind memory: visual representations of slavery in England and America, 1780-1865. Manchester, UK: Manchester University Press, 2000, p. 9 e 10 (tradução do autor).
} 
Presente na imprensa britânica, tal variedade de imagens alterou-se com a ampliação das políticas antiescravistas, no início dos oitocentos. Das imagens sobre o trabalho escravo, dos escravizados no trabalho em plantações, de fugas, lentamente começaram a ganhar espaço escravizados em espaços urbanos, práticas sociais e culturais e ações de resistência em meados do século XIX: "os escravos emergem agora como grupos de pessoas capazes de sustentar atividades culturais e artísticas autônomas". ${ }^{35}$ Outras, como imagens sobre punições, castigos e rebeliões de escravos mantiveram-se frequentes, oscilando sua interpretação, a depender da mídia e dos interesses políticos.

\section{O Rio que Harring viu ${ }^{36}$}

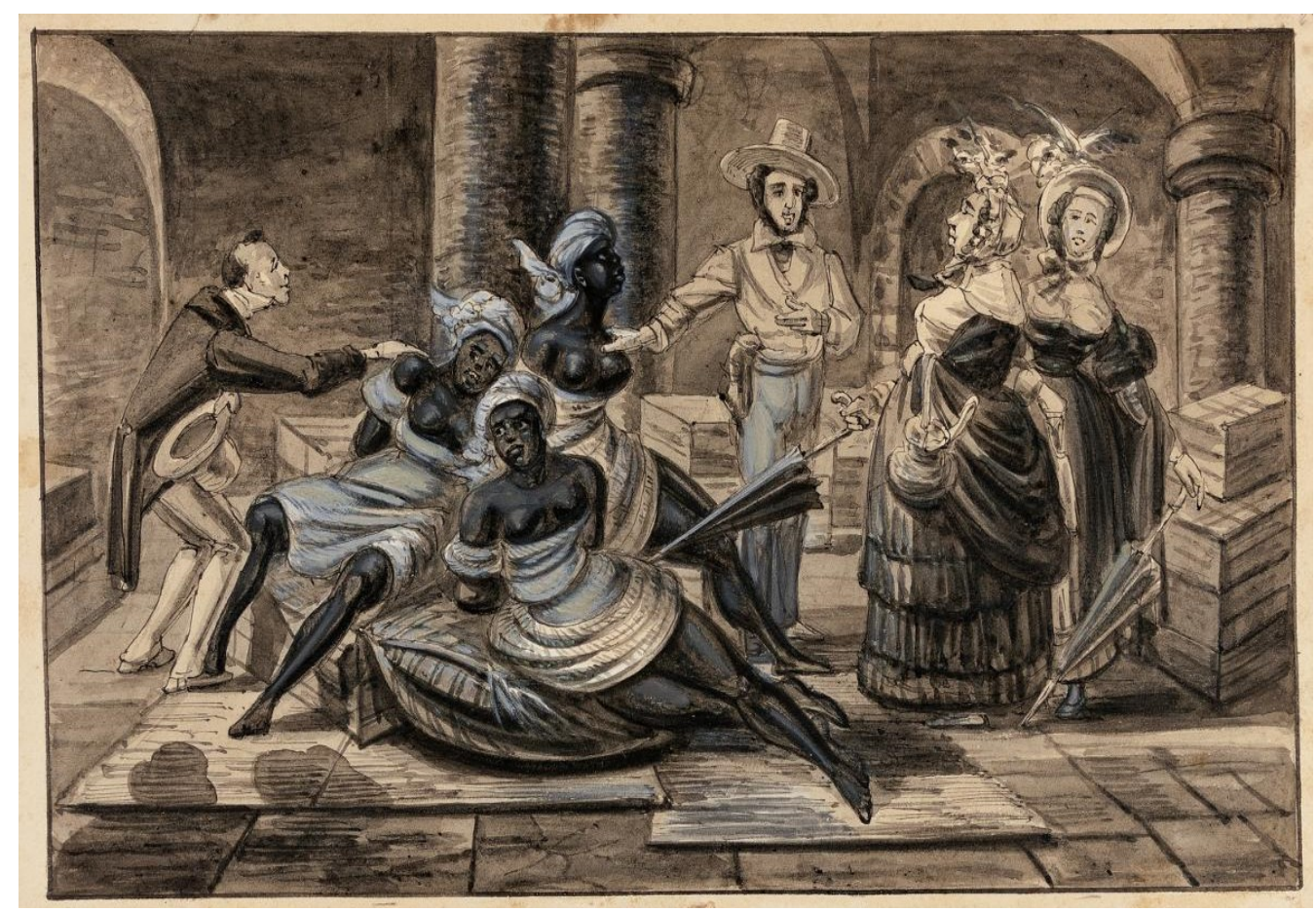

Figura 2. "Inspeção de negros recentemente desembarcados da África”. "O homem de negócios da Sra. Quickly". Paul Harro-Harring, c.1840, nanquim, aquarela e guache sobre papel, 20,1 x $32,4 \mathrm{~cm}$.

Não temos, no momento como avaliar, a recepção do trabalho de Harro-Harring em meio a essa cultura visual em expansão. O número de imagens que tentavam apresentar a escravidão cresceu muito a partir dos anos de 1830. Para o historiador da arte estadunidense Albert Boime, as imagens chegavam ora como uma alegoria do sofrimento das populações escravizadas, ora pelo

\footnotetext{
${ }^{35}$ Idem, ibidem, p. 10.

36 Título da chamada da coluna de Lago Burnet, publicado no Jornal do Brasil, Rio de Janeiro, 17 dez. 1965, Caderno B, p. 2. A coluna informava a publicação do álbum Tropical sketches from Brasil pelo IHGB: "O Rio que Harring viu", assinado por Lago Burnett, onde se lê: "... excelente desenhista, com um traço firme e seguro colecionou, com rara felicidade aspectos da vida dos escravos, desenhos esses que têm o sabor e espontaneidade de instantâneos que hoje seriam colhidos por um repórter, com uma câmara de 35 milímetros".
} 
tratamento artificial que conferia domesticidade às práticas da servidão, tratadas em cotidianos sociais calculados ou romantizados. ${ }^{37}$ Ao observamos as vinte e quatro aquarelas podemos perceber algumas particularidades do "olhar" de Harro-Harring, nessa mesma direção. Alguns grupos temáticos são recorrentes. No primeiro grupo temos cenas de interiores com forte acento narrativo, cujo objetivo era expressar as relações sociais conflitantes entre senhores e escravizados. Dentre elas temos as pranchas dedicadas à comercialização de escravos, cenas que transitam entre o comedimento cotidiano e a violência sobre negros e mestiços escravizados (figura 2).

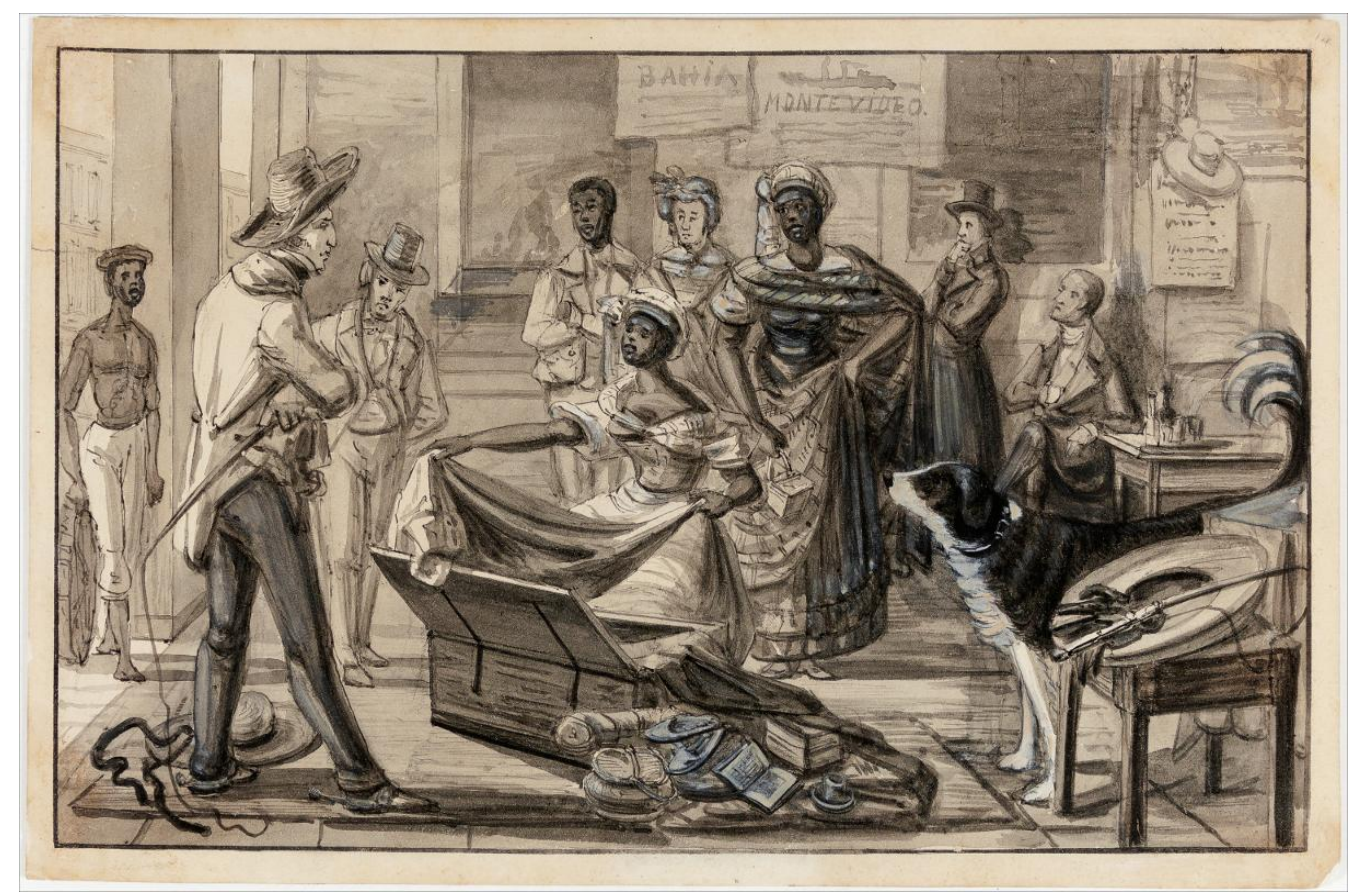

Figura 3. "A negra acusada de roubo". Paul Harro-Harring, c.1840, nanquim, aquarela e guache sobre papel, $20,6 \times 32,3 \mathrm{~cm}$.

Nesse primeiro grupo está, provavelmente, a imagem mais comentada pela historiografia brasileira recente, "A negra acusada de roubo" (figura 3), graças ao relato publicado pelo viajante. ${ }^{38}$ Harro-Harring relata a compra da liberdade de uma jovem escrava por uma negra livre mais velha. O relato é detalhado, delineia o ambiente e os personagens presentes numa hospedaria. Após o trâmite, o ex-dono da escrava, ao vê-la sair com seus pertences em um baú, trata de acusá-la de roubo. O artista escreve: "A acusada, entretanto, mostrou-se muito diferente da pessoa subjugada e quase inerte que até então aparentava ser. Seus olhos estavam inflamados, os lábios lívidos e as faces mostravam a palidez peculiar dos negros quando profundamente provoca-

${ }^{37}$ Cf. BOIME, Albert. The art of exclusion: representing blacks in the nineteenth century. Washington: Smithsonian Institution Press, 1990, p. 36 e 37.

${ }^{38}$ Cf. MACEDO, Rafael Gonzaga de. Paul Harro-Harring e a revolução: correlações possíveis. Anais do VII Encontro de História da Arte. Campinas: Unicamp, 2011. 
dos". ${ }^{39}$ Após vasculhar os pertences da recém-liberta, o acusador "humilhado com toda aquela cena, murmurou umas poucas palavras de desculpas". ${ }^{40}$ Harro-Harring detém-se demoradamente sobre o episódio que escolheu para publicar em Esboços tropicais do Brasil e completa:

Voltei para o meu lar europeu e a minha solidão, tão logo os negócios que me levaram ao Rio de Janeiro o permitiram, mais ainda refletindo sobre o ocorrido. Tudo era novidade para mim e serviu para revelar-me alguns traços do caráter daquela raça oprimida, que me encheram de surpresa e respeito. Não conseguia retomar meus afazeres normais. Era como se a mão de um pintor se visse impedida de trabalhar, em virtude de suas amargas lembranças. O duro destino do povo negro, eternamente exposto ao extremo insulto e à baixeza dos brancos, me perseguia, conquanto este mesmo sentimento era aliviado pelo contraste representando pelos bons e nobres atos daquela irmandade negra. ${ }^{4}$

Os castigos enfrentados pelos escravizados no Brasil foram um tema recorrente de outros viajantes, mas o traço caricatural de Harro-Harring, por vezes irônico e jocoso, estabeleceu uma dualidade entre a "baixeza" dos brancos e a "nobreza" dos negros, em toda a seu sofrimento presenciado pelo artista, que se fez retratar em "Velho escravo negro apanhando de sua senhora por um mal-entendido" (figura 4). Esta obra, de fato, já pertence a um grupo distinto de aquarelas, onde o espaço exterior da cidade e sua paisagem são representados. Mesmo aqui o artista enfatiza as atividades cotidianas, esclarecendo sobre os diferentes níveis de trabalhos realizados pelas populações negras no Rio de Janeiro. Não passa desapercebida a ênfase que ele deu ao negócio e ao transporte do café, produto que dominaria a pauta das relações comerciais entre Brasil e a Europa nas décadas seguintes ${ }^{42}$, o que, em contramão, alimentou e estendeu o tráfico de escravos (figura 5). Em todas essas pranchas, o viajante criou uma dualidade entre corpos, feições e expressões de brancos e negros. Utilizando os mesmos recursos formais para comunicar os valores morais dos algozes e de negros libertos ou escravizados. ${ }^{43}$

\footnotetext{
${ }^{39}$ HARRO-HARRING, Paul apud MARTINS FILHO, Eneas (org.), op. cit., p.12.

${ }^{40}$ Idem, ibidem, p. 15.

${ }^{41}$ HARRO-HARRING, Paul apud MARTINS FILHO, Eneas (org.), op. cit., p. 15.

${ }^{42}$ Cf. BETHELL, Leslie, op. cit.

${ }^{43}$ Todas as imagens das pranchas que compõem Tropical sketches from Brasil estão disponíveis no site oficial do Instituto Moreira Salles. Ver <http://201.73.128.131:8080/portals/\#/search?filtersStateId=16>. Acesso em 10 abr. 2020.
} 


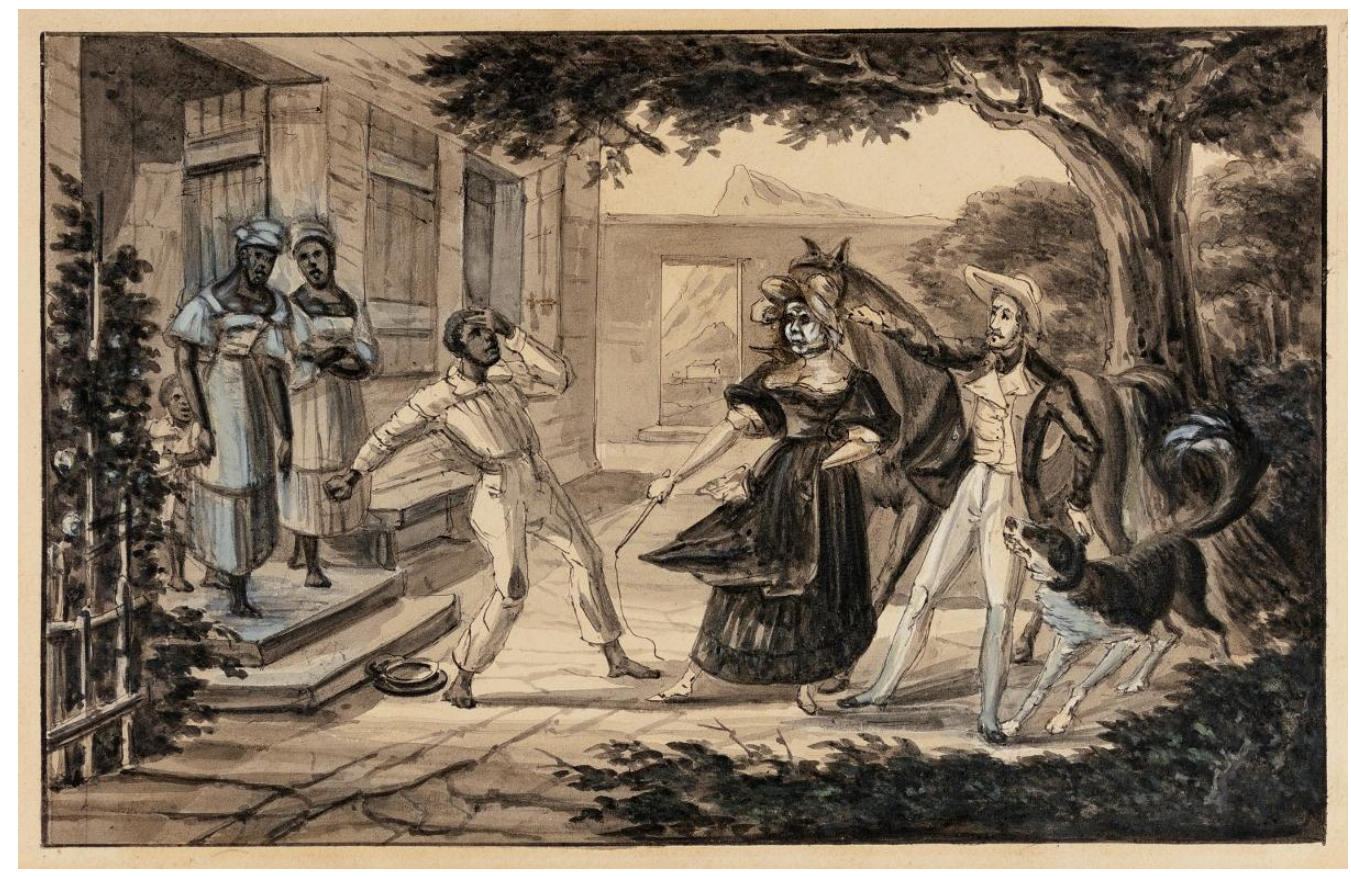

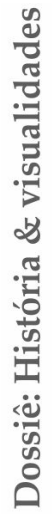

Figura 4. "Velho escravo negro apanhando de sua senhora por um mal-entendido (O viajante, seu cavalo e seu cão Fingal)". Paul Harro-Harring, c.1840, nanquim, aquarela e guache sobre papel, $20,6 \times 32,3 \mathrm{~cm}$.

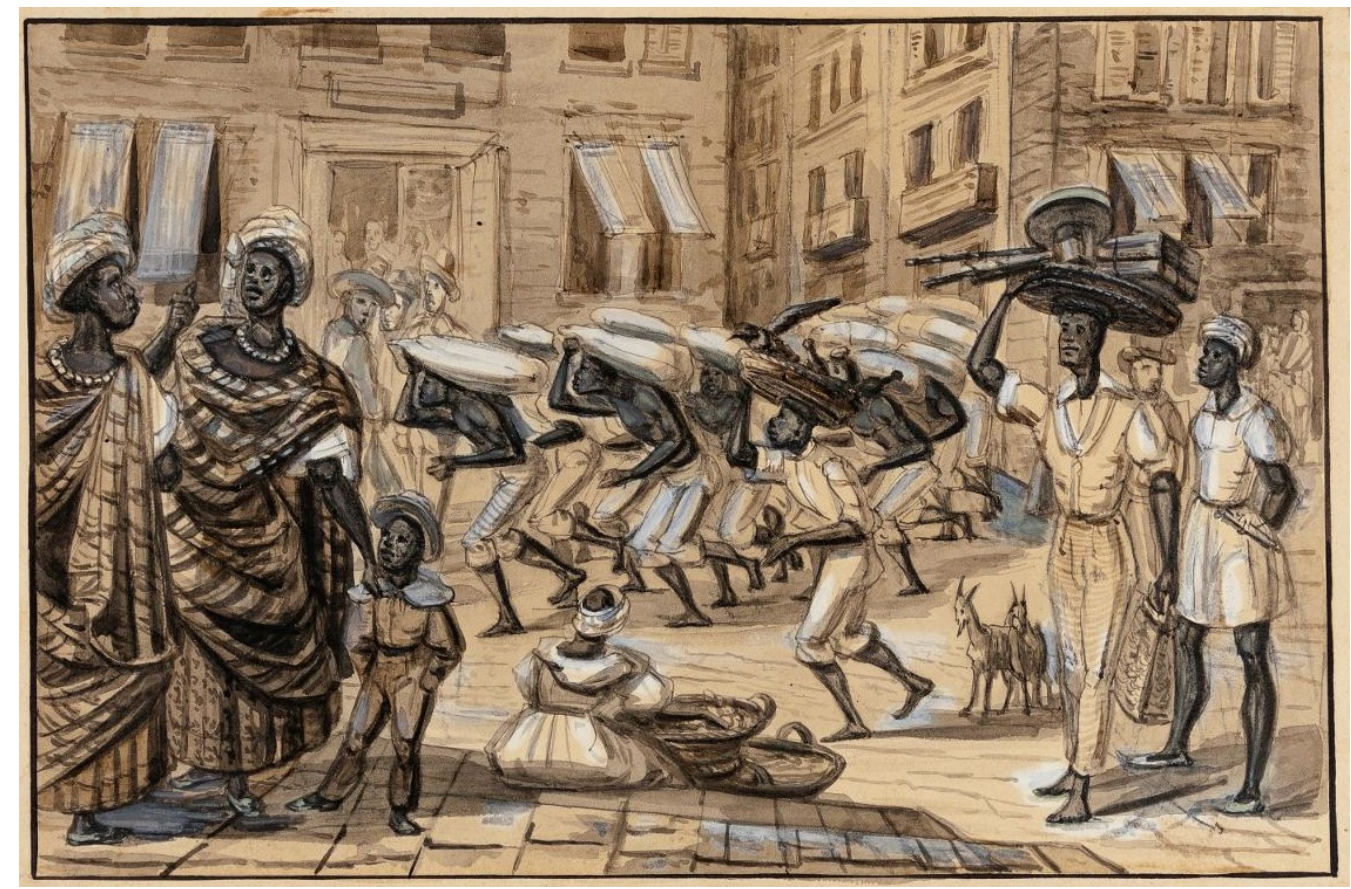

Figura 5. “Cena na Rua Direita. Negros carregando café”. Paul Harro-Harring, c.1840, nanquim, aquarela e guache sobre papel, $21,0 \times 32,0 \mathrm{~cm}$. 
O terceiro grupo de imagens, formado por nove obras, apresentam o transporte de cabotagem no litoral fluminense, reunindo escravos, traficantes, pescadores, militares entre outros. "Seus desenhos permitem-nos deduzir que visitou o litoral fluminense, tendo estado em Barra de São João e nas Ilhas de Sant'Ana, ao largo de Macaé". ${ }^{44}$ Novamente Harro-Harring permite-se construir um jogo de oposições entre narrativas. $\mathrm{O}$ tratamento conferido em "Ilhas de Sta. Anna. Desembarque de negros escravos" (figura 6) e "Embarcação da Guarda Mor" (figura 7), faz com que a primeira seja sempre privilegiada pelo contundente chibatada proferida sobre um escravo de costas que emoldura e rompe com paisagem ao fundo. A ênfase dada ao mar como forma de representar o trabalho, o transporte e a paisagem do Rio de Janeiro não parece ser uma escolha trivial quando relacionada às demandas e às pretensões políticas do The African colonizer.

Sabemos que o artista vendeu pinturas no Rio de Janeiro, ao menos em uma ocasião documentada pelo Jornal do Commercio em 21 de julho de 1840, o que nos impõe a suposição de que as obras publicadas em Londres passaram por um processo de seleção de diferentes versões:

Frederico Guilherme fará leilão, amanhã, sexta-feira 24 corrente, na sua casa, rua do Ouvidor n.84, por conta do Ilm. Sr. Harro-Harring, Dinarmaquez, que se retira para fora, de 15 lindos painéis originaes, pintados pelo dito Ilmo Sr., sendo 4 com vistas da Bahia do Rio de Janeiro, tomadas de Santa Thereza, formando hum panorama de 8 pés de comprimento; huma vista da costa do Brazil, tomada das Ilhas de Santa Anna; 6 vista da Italia [...] Todos estes painéis, acabados com talento e de perfeitíssima exactidão, merecem a attenção dos amantes da boa pintura, que os poderão examinar da casa anunciante, onde estão desde já à disposição dos curiosos. ${ }^{45}$

\footnotetext{
${ }^{44}$ Apud HARRO-HARRING, Paul. Paul Harro-Harring: esboços tropicais do Brasil. Rio de Janeiro: Instituto Moreira Salles, 2006, p. 35.

${ }^{45}$ Apud Jornal do Commercio, n. 0191, Rio de Janeiro, 21 jul. 1840, p. 4 (“Leilão extraordionario dos lindos painéis originaes, pintados pelo Ilmo. Sr. Harro-Haring, hábil pintor dinamarquez que se retira para sua pátria"). A mesma notícia pode ser encontrada no O Despertador, do dia 24 jul., p. 4 . O Jornal do Commércio indica uma nova exposição na edição de 26 jul. 1843. Na edição 210, do dia 10 ago. 1843, o periódico anuncia na página 4: "Roga-se aos Senhores proprietários dos bilhetes de acções da colecção de quadros de M. Harro-Harring que irão reunir-se no Hotel do Norte, sexta-feira 11 do corrente, às 5 horas da tarde". A presença da pintura óleo Cena em uma venda: marinheiros negociam com negras, de 1843, no acervo do IMS nos adverte para a tradução dos esboços em outras linguagens artísticas e sua circulação no comércio das belas artes no século XIX. Aliás, o tratamento "orientalista" conferido à pintura merece uma investigação pormenorizada.
} 


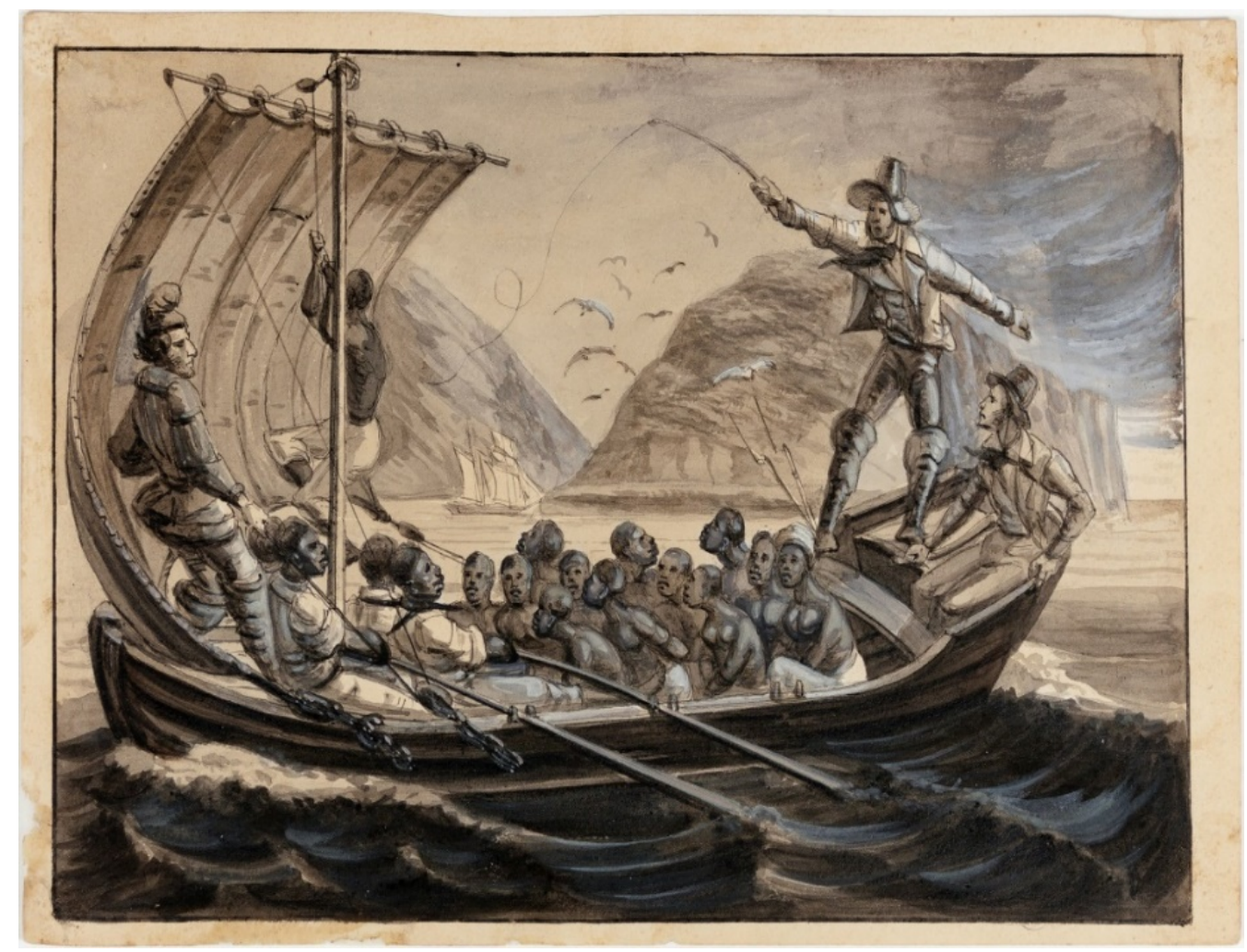

Figura 6. "Ilhas de Sta. Anna. Desembarque de negros escravos". Paul Harro-Harring, nanquim, aquarela e guache sobre papel, $21,3 \times 31,8 \mathrm{~cm}$.

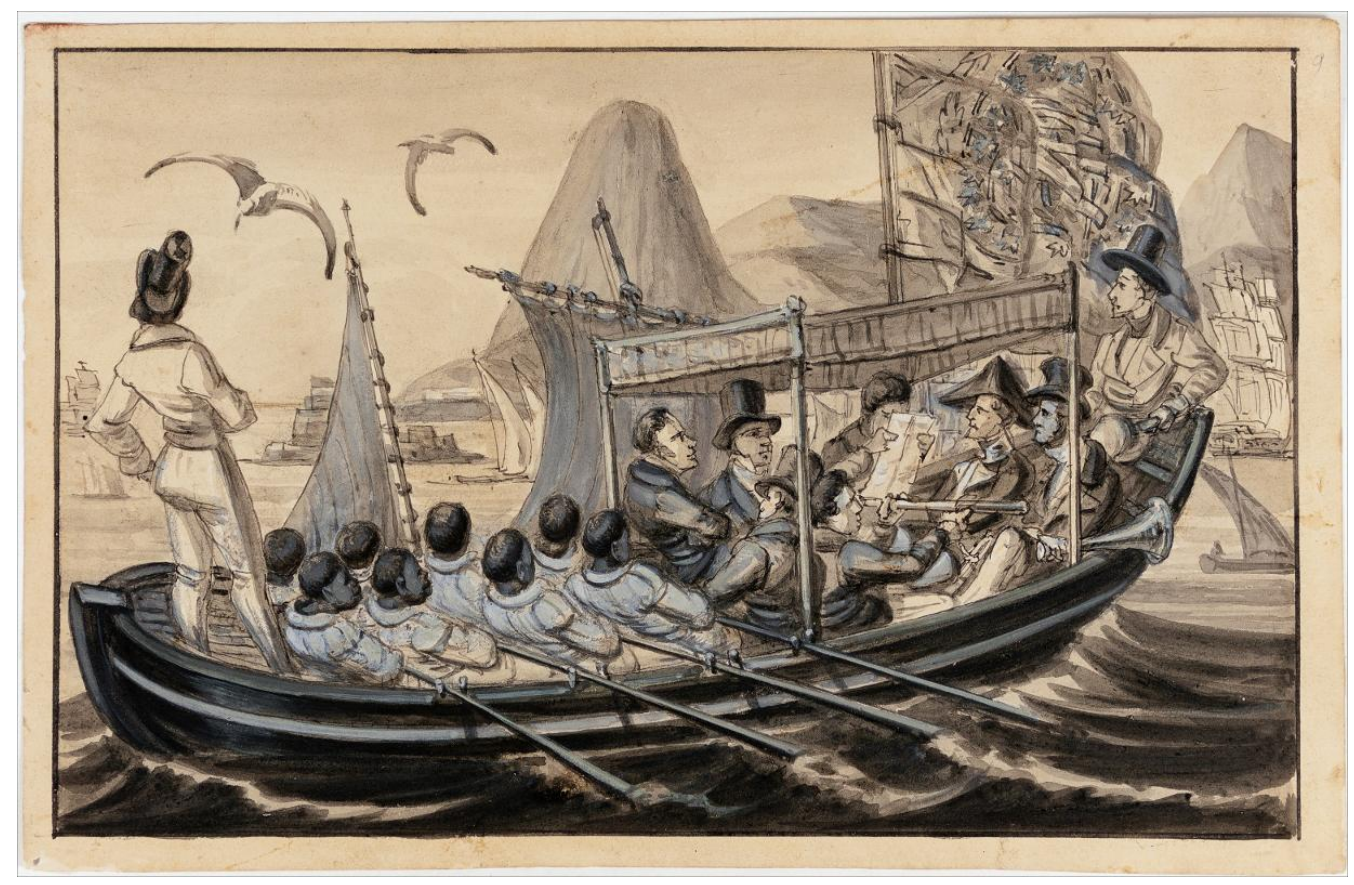

Figura 7. "Embarcação da Guarda Mor (Capitania dos Portos) do Rio Janeiro". Paul HarroHarring, c.1840, nanquim, aquarela e guache sobre papel, 20,5 x 32,4 cm. 
Atividades marítimas aliadas com um certo olhar "turístico", por vezes melancólico, parecem ter sido preocupação dos editores. Neste último grupo está "Vista da costa oeste da Baía da Guanabara do Rio de Janeiro" (figura 1), que nos lembra da formação do pintor em Dresden e Berlin, próxima à de Caspar David Friedrich, uma especulação apoiada no diálogo documentado por Everett $(1884,342)$ entre Harro-Harring e o pintor norueguês Johan Christian Dahl, amigo de Friedrich. ${ }^{46}$ Há, ainda, uma única aquarela, “Dança de negros. Músicos tocando instrumentos de seus países", a representar a população negra sem os elementos de identificação recorrentes do trabalho e/ou da escravidão. A existência de uma única imagem dedicada às práticas culturais é incomum nas publicações correntes do período, tão interessadas em apresentar hábitos e costumes de nativos, seja pela literatura, seja pela produção iconográfica dos viajantes. ${ }^{47} \mathrm{O}$ que reforça o caráter programado da produção do artista e as intenções políticas de Esboços tropicais do Brasil.

Por tudo o que vimos, em seu conjunto, as aguadas de Harro-Harring possuem correspondência com outros tipos de imagens com finalidade políticas produzidas no século XIX. A seu modo, o viajante dinamarquês construiu uma obra que vinculava os trópicos como um lugar do exótico, e sua narrativa sobre os conflitos gerados pela escravidão segue a mesma lógica. Certamente, outras questões se abrem quanto à estada do artista na Argentina ${ }^{48}$, na GrãBretanha e nos Estados Unidos, onde continuou sua atividade de escritor e pintor, por volta de 1843, e na Alemanha, onde fundou o jornal revolucionário O Povo. Quanto a experiência no Brasil afetou a produção literária e visual nos anos posteriores é algo que permanece em aberto.

Em nosso ambiente de pesquisa, também, podemos nos questionar como as imagens Harro-Harring de coadjuvantes passaram a protagonistas na "ilustração" da revisão da história da escravidão brasileira, especialmente da literatura dedicada à Segunda Escravidão. Na mesma direção, ainda, é pertinente questionar como a demanda por novas interpretações sobre a escravidão e seus efeitos sociais realinharam as aquarelas no vasto acervo do IMS; o que exigirá de pesquisadores compreender as motivações das primeiras coleções, em especial das coleções Brasilianas naquela instituição. Do mesmo modo, a visibilidade das aguadas de Harro-Harring, bem como o impacto da produção de outros artistas-viajantes menos conhecidos no imaginário brasileiro e estrangeiro sobre a escravidão permanece pouco estudado. Enfim, os trabalhos desse artista militante nos oferecem elos preciosos para compreender como nas últimas décadas historiadores veem reagindo a um dos problemas mais urgentes de nossa contemporaneidade: a insistente amnésia que toma a história das violências em nosso país.

Artigo recebido em 30 de maio de 2020. Aprovado em 20 de julho de 2020.

\footnotetext{
${ }^{46}$ Cf. MACEDO, Rafael Gonzaga de. Paul Harro-Harring e a revolução: correlações possíveis, op. cit., p. 43.

${ }^{47}$ Cf. BOIME, Albert, op. cit., e BELlUZZO, Ana Maria. O Brasil dos viajantes. São Paulo-Salvador: Metalivros/Fundação Odebrecht, 1994.

${ }^{48}$ A passagem pela Argentina entre 1841 e 1842 rendeu material para o romance Dolores: a historical novel of South America, with episodes on Politics, Religion, Socialism, Psychology, Magnetism, and Sphereology, publicado em 1947, pelo autor em Nova York.
} 